\title{
Adult Educators' Voices on the use of Traditional Medicine: the Case of Shanty Compounds in Lusaka Zambia
}

\author{
${ }^{1}$ Department of Adult Education, Zambian Open University, Zambia \\ ${ }^{2}$ Department of Mathematics and Science Education, Copperbelt University, Zambia \\ ${ }^{3}$ Department of Secondary Education, Zambian Open University, Zambia \\ ${ }^{4}$ Department of Adult Education and Extension Studies, University of Zambia, Zambia \\ ${ }^{5}$ Department of Primary Education, Zambian Open University, Zambia
}

Daniel L Mpolomoka ${ }^{1 *}$, Rex L Sampa ${ }^{2}$, Mbono Dube ${ }^{3}$, Phyllis Iñutu Sumbwa ${ }^{4}$ and Michael M Mabenga ${ }^{5}$

Submission: January 15, 2018; Published: February 09, 2018

*Corresponding author: Daniel L Mpolomoka, Zambian Open University, School of Education, Zambia, Tel: +260 977753725 ;

Email: mpolomokadaniel@yahoo.com

\begin{abstract}
This study sought to explore the emerging concerns among men and women trading in markets regarding use of traditional medicines. The study is informed by findings of a phenomenological study that took place from 2006 to 2016. The phenomenological data was collected with retrospective data, triangulation and document review. The majority of inhabitants in the shanty dwelling places of the city of Lusaka enjoy the 4, 600 flowering plant species, where 211 are endemic. Mwitwa [1] contends that over $75 \%$ of all Zambians benefit from traditional medicine voluntarily or involuntarily.

The inhabitants who are migrants from the rural areas come with hard to change, stereotype mind-sets regarding conventional-traditional medicine with the majority seeming to prefer the use of traditional herbs to conventional medicine (herein also referred to as biomedical medicine). The findings were that there is general ignorance regarding the side effects of using traditional medicine. One's level of education does not determine one's use of traditional medicine. Participants of the study were of the view that access and use of traditional should not be regulated. Media advertisements of traditional medicine are unregulated and uncertainty surrounds the efficacy of traditional medicine. Use of traditional medicine in both men and women was often motivated by love and sexually related reasons.
\end{abstract}

Keywords: Traditional medicine; Shanty compound; Adult educator; Conventional medicine

\section{Introduction}

This study sought to explore the emerging concerns among men and women trading in markets regarding use of traditional medicines. Globally the region of Southern Africa is recognized as a centre of biodiversity richness and endemism. The region possesses 66, 888 plant species i.e. inclusive of medicinal and out of these 3,666 are endemic (WWF, 2009). Approximately $80 \%$ of the population in the region depends on medicinal plants for primary health care. Governments in Southern Africa have recognised the importance of traditional medicine in their health caresystems; aswellastheneed to provide enablingadministrative and governance structures for traditional medicinal practice. Mwitwa [1] contends that over $75 \%$ of all Zambians benefit from traditional medicine voluntarily or involuntarily. In the developing world, traditional medicine has been recognized by the World Health Organization for all intents and purposes as the economical substitute for biomedicine [2]. Consequently, the Zambian government has looked to incorporate "traditional healers" locally referred to as $n g^{\prime}$ anga with their biomedical counterparts in the national health care system (Sugishita) [2] leading to the formation of the Traditional Healers Association; and the Traditional Health Practitioners Association of Zambia (THPAZ), WHO [3,4].

\section{Methodology}

A phenomenological research design was employed that took a decade, 2006 to 2016. The paper blends the phenomenological data collected with retrospective data, triangulation and document review. It interviewed 100 men and women (50 each, sampled gender sensitively; and 10 from each market) marketers in five markets, 20 from each market: Chawama, Misisi, Kanyama (Masauko market), Garden Compound and John 
Lain. Participants were selected conveniently. Findings were analyzed thematically.

\section{Findings and Discussion}

The findings are presented and discussed under six themes as emanated from the findings of the study.

\section{Theme 1: Use and access concerns of traditional medicine}

Five striking concerns emerged. These bordered on use of traditional medicine by both men and women in five markets across five shanty compounds covered in the study. The concerns were: unknown expiry date, unclear dosage, duration of intake, side effects and unknown instructions (intake plan). There were as many participants (77 out of the 80 ) who openly said that traditional medicines have side effects as they were those who said they do not. Participants categorically bemoaned the apparent ignorance exhibited by the general populace of indulging in use of traditional medicine without full knowledge of side effects. For men who sought enlargement of manhood, it was revealed that side effects were long lasting, just like in women who relentlessly use traditional herbs on their womanhood with impunity.

\section{Theme 2: Level of education determines one's use of traditional medicine}

The overarching question asked here was: does level of education determine one's use of traditional medicine? Findings reveal that one's level of education do not determine one's use of traditional medicine. In fact, the majority of participants (60, 40 women and 20 men), all grade twelve school leavers and possessing tertiary certificates admitted consulting and using traditional medicine. Their unanimous views below are indicative:

a. Ulabomba umuti wacimuntu (ChiBemba) Traditional medicine works (English Version). [Female, aged 44, Kanyama; Male, aged 50, Garden House; Female, aged 38, Misisi Compound]

b. Mulyani wasintu kisifanu. Uzwa ku Mulimu (Silozi), Traditional medicine performs wonders. It is God given. (English Version), [Male, aged 53, John Lain; Female, aged 36, Kanyama; Female, aged 41, Misisi Compound]

c Munkhwala wa ci munthu ndi wamphanvu ngako. uthandiza (Chinyanja) Traditional medicine is very powerful and helps us (users). (English version) [Female, aged 37, Chawama Compound; Female, aged 44, Kanyama; Male, aged 53, Misisi Compound]

\section{Theme 3: Traditional medicine, regulation and the law}

All the participants did not find it necessary to regulate access and use of traditional medicine. Participants in the late $30 \mathrm{~s}$ and 50s, recounted how they enjoyed use of traditional medicine without regulation and restriction. It is noteworthy that the Food and Agriculture Organization (FAO, 2003) reveals that international trade in medicinal plants was worth $\$ 4.4$ million in Zambia. However, both print and electronic media reports highlighted protracted views from the Traditional Healers Association and Biomedical practitioners regarding the necessity of regulation of traditional medicine. Furthermore, there is no law in Zambia that regulates traditional medicine. Phiri [5] confirms that the Zambia Medicine Regulatory Authority (ZAMRA) has no control over what traditional healers sell.

\section{Theme 4: Traditional medicine advertisements}

Findings revealed unregulated media advertisements of traditional medicine. In many instances, all participants observed that the adverts are very questionable, elusive and deceptive. Claims of 'bringing back lost lover', 'making an individual rich' were cited as unrealistic and unattainable. Phiri [5] states that stores selling traditional medicines are common in Zambia, but government regulators are unable to control the industry.

\section{Theme 5: Efficacy}

All the participants interviewed expressed uncertainty when asked about the efficacy of traditional medicine. All however, acknowledged traditional medicine with reverence. This is because their elder men and women handed this knowledge of traditional medicine down to them with instructions to pass it down to generations to come. For three quarters of the participants, traditional medicine is the original medicine and is unmatched to date. However, in an open letter, Engineer Phiri [6] challenged the Association of Medical professionals in Zambia to investigate the herbal remedies popularised on the Zambian market.

\section{Theme 6: reasons for use of traditional medicine}

According to the majority of male participants, they use traditional medicine to enlarge their manhood, increase their sperm production, healing, cast out demons, protection at work, making an individual rich' and good luck. However, there were a number of instances recounted when the medicine backfired and did not yield anticipated results when used. This is confirmed by the noted increase in media reports regarding cases of traditional medicine use that backfire. The reasons advanced by men were almost similar to those put forward by women. Unlike men, in women, use of traditional medicine was motivated by their need to keep warm (in bed), tighten their womanhood, bring back lost lovers, keep their lovers and, or husbands, improve milk secretion (in breastfeeding mothers) and easy delivery (in pregnant women). Maluma et al [7]. also established that traditional herbal medicine is used by pregnant women to accelerate labour.

\section{Conclusion}

Men and women in the shanty township communities of Lusaka, Zambia prevalently used and relied on traditional herbal medicine for purposes related to enhancing their sexual activity 
even though they harbour uncertainty on its efficacy. Reliance on traditional medicine is not influenced by the level of education. There is need for government to regulate the use of traditional medicine and advertisements as well especially that more often than not the dosage and duration of use is not clear nor are the side effects of using traditional medicine known.

\section{Recommendations}

1. Government should formulate a Legal Framework to regulate access and use of traditional medicine.

2. Government should regulate media adverts made by traditional medicine proprietors.

\section{References}

1. Mwitwa J (2009) The status of traditional medicinal plant practice in the Miombo eco-region of southern Africa: Zambia Case Study. Consultancy report prepared for WWF Southern Africa Regional Programme Office, Lusaka, Zambia.
2. Kaori S (2009) Traditional Medicine, Biomedicine and Christianity in Modern Zambia. The Journal of the International African Institute 79(3): 435-454.

3. World Health Organisation (2003) Traditional Medicine. WHO Fact Sheet No. 134. Geneva, Switzerland.

4. WHO (2005) National policy on traditional medicine and regulation of herbal medicines. Report of a WHO global survey. World H, France, pp. 1-168.

5. Phiri P (2017) In Zambia, Business is booming for street sales of prescription, traditional drugs. Global Press Journal, Washington, USA.

6. Phiri C (2015) Open Letter: Dear Dr Mujajati -Herbal and Traditional Medicine.

7. Maluma S, Kalungia CA, Hamachila A, Hangoma J, Munkombwe D (2017) Prevalence of Traditional Herbal Medicine use and associated factors among pregnant women of Lusaka Province, Zambia. Journal of Preventive and Rehabilitative Medicine 1(1): 5-11.

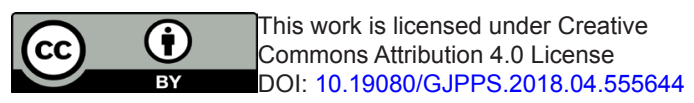

